\title{
Residual Stresses in Multi-pass Butt-welded Tubular Joints
}

\author{
Nico Hempel ${ }^{\mathrm{a}}$, Thomas Nitschke-Pagel ${ }^{\mathrm{b}}$ and Klaus Dilger ${ }^{\mathrm{c}}$ \\ TU Braunschweig, Institute of Joining and Welding, Langer Kamp 8, D-38106 Braunschweig, \\ Germany \\ an.hempel@tu-braunschweig.de, 'bt.pagel@tu-braunschweig.de, 'ck.dilger@tu-braunschweig.de
}

\begin{abstract}
Keywords: Welding, Residual Stresses, Tubular Joint, X-ray Diffraction, Hole-Drilling Method
\end{abstract}
\begin{abstract}
In this study, the mechanics of the residual stress development in multi-pass butt-welded joints of ferritic-pearlitic steel pipes are investigated. Therefore, the effects of the welding process and its parameters, as well as the impact of the preheating temperature on the residual stress state are studied by determining the temperature profile during welding and performing X-ray diffraction measurements on the pipes' inner and outer surfaces. Additionally, residual stress depth distributions are determined using the incremental hole-drilling method. The residual stress distributions can be explained by phase transformations and thermal shrinkage, the latter being the governing mechanism in the tubular geometry of the welds.
\end{abstract}

\section{Introduction}

Current fatigue design codes [1,2] are unnecessarily conservative by assuming that residual stresses occurring in welded joints generally take the value of the yield strength, which cannot be confirmed by actual experimental stress analyses, see e.g. [3]. Moreover, in the design codes, residual stress is attributed the same effect on fatigue strength as mean stress, even though residual stresses can be subject to relaxation during loading. Therefore, one aim of current research is to develop design standards that account for the effects of residual stresses on the fatigue strength while simultaneously providing for an efficient use of material. A necessary requirement is the identification of the residual stresses resulting from the welding process and remaining in the material after relaxation during service, ultimately through numerical simulations using an experimentally validated material model. In a first step, the mechanics responsible for the residual stress development in multi-pass butt-welded joints of ferritic-pearlitic steel pipes are studied experimentally using X-ray diffraction and the incremental hole-drilling method; an investigation of residual stress stability under cyclic loading and a comparison with concurrent simulations for validation purposes will be performed later on. Tubular butt welds have been chosen because these joints are subject to deformation constraints not found in plane weldings of plates, thus reflecting the character of actual components much better. Moreover, tubular welds are of utmost importance to several branches of industry, e.g. offshore technology or the construction of cranes.

\section{Experimental work}

Welding Experiments. Ferritic-pearlitic steel tubes of $\mathrm{S} 355 \mathrm{~J} 2 \mathrm{H}+\mathrm{N}$ were used for the welding experiments, see Fig. 1. The specimens were machined on the outer and inner surface in order to remove the rolling skin and geometrical imperfections of the tubes, resulting in an outer diameter of $101 \mathrm{~mm}$ and a wall thickness of $8 \mathrm{~mm}$. A v-shaped groove was introduced at half-length as a weld preparation, leaving a thin link between the two halves of the specimen that guaranteed well-defined clamping conditions and prevented misalignment of the two halves. Before welding, the specimens were stress relieved thermally at $600^{\circ} \mathrm{C}$ for 30 minutes and cooled uniformly at about $1{ }^{\circ} \mathrm{C} / \mathrm{min}$.

The specimens were metal active gas (MAG) welded with two passes in flat position using a rotary table; the filler metal was G $464 \mathrm{M} \mathrm{G} 4 \mathrm{Si}$. The nominal energy inputs were $11 \mathrm{~kJ} / \mathrm{cm}$ for the root pass and $10.5 \mathrm{~kJ} / \mathrm{cm}$ for the second pass. Both passes were welded in the same direction and started at almost the same point. The preheating and interpass temperatures were varied between 
room temperature, $150^{\circ} \mathrm{C}$ and $300^{\circ} \mathrm{C}$. Temperature measurements were performed in the vicinity of the weld using $\mathrm{Ni} / \mathrm{CrNi}$ thermocouples (type $\mathrm{K}$ ) that were placed close to the weld toe and in the heat-affected zone (HAZ) at locations in every $90^{\circ}$ along the specimen's circumference.

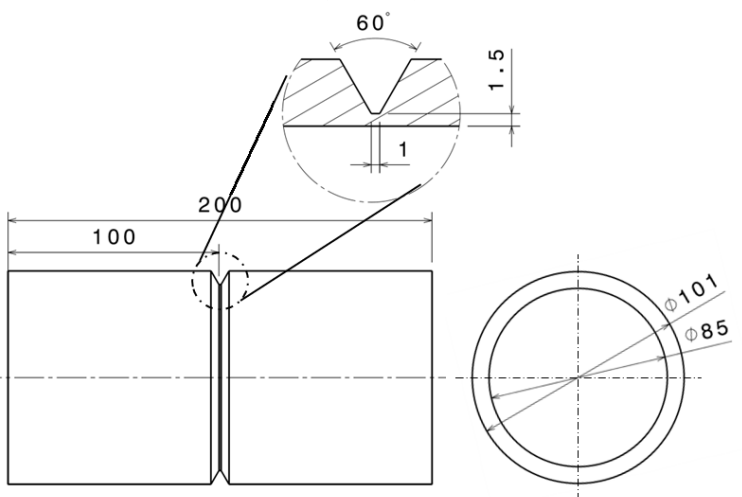

Figure 1: Tubular specimen for welding

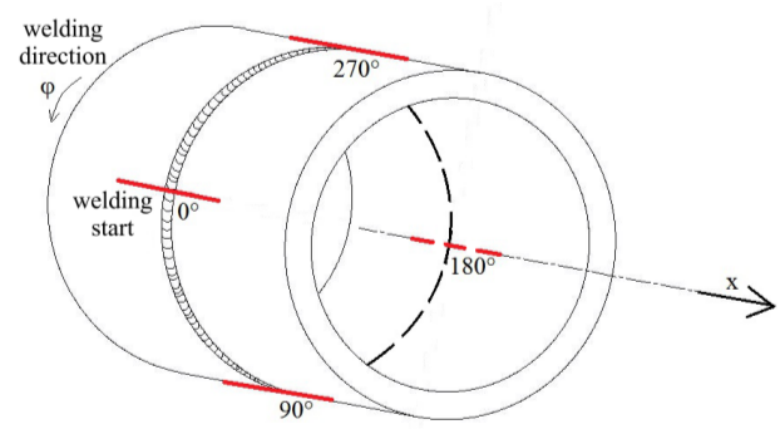

Figure 2: Locations of XRD measurements

Residual Stress Analysis. Measurements of residual strains were performed by X-ray diffraction (XRD), using an $\Omega$-diffractometer and analyzing the shift of $\mathrm{Cr}-\mathrm{K}_{\alpha}$ radiation interference lines originating from $\{211\}$ lattice planes of ferrite, bainite or martensite. An X-ray tube voltage of $35 \mathrm{kV}$ and a current of $30 \mathrm{~mA}$ have been used; the diameter of the collimator was $2 \mathrm{~mm}$. The interference line was recorded for eight tilt angles $\psi$ of $0^{\circ}, 13^{\circ}, 18^{\circ}, 27^{\circ}, 33^{\circ}, 39^{\circ}, 42^{\circ}$ and $45^{\circ}$ in a $2 \theta$ interval of $151^{\circ}$ to $161^{\circ}$. The strains were derived from the shift of the interference line's center of gravity by the $\sin ^{2} \psi$ method and used to compute the residual stresses by means of the X-ray elastic constants $\mathrm{s}_{1}=-1.33 \cdot 10^{-6} \mathrm{~mm}^{2} / \mathrm{N}$ und $\mathrm{s}_{2} / 2=6.08 \cdot 10^{-6} \mathrm{~mm}^{2} / \mathrm{N}$.

The residual stresses were determined both in hoop and axial direction in a distance of up to 30 $\mathrm{mm}$ on both sides of the weld centerline. Where the assumption of symmetry was appropriate, measurements were only performed on one side. In the weld seam and the HAZ the distance between two measuring points was $1 \mathrm{~mm}$ due to the expected stress gradients in these areas. At a greater distance from the centerline measuring points were set every 2 to $5 \mathrm{~mm}$. Measurements were taken on the inner and outer surfaces of the pipes along lines perpendicular to the welding direction at every $90^{\circ}$ along the specimens' circumference, see Fig. 2, with an average penetration depth of 5 $\mu \mathrm{m}$. The inner surfaces were accessible after sectioning the tubes into four quarters, the released stresses being monitored by strain gauge measurements. Fig. 2 also shows the circumferential angle $\varphi$, marking welding start and welding direction, as well as the axial coordinate $\mathrm{x}$ that specifies the distance from the welding centerline.

Residual stress analyses using the incremental hole-drilling method according to ASTM standard E837-08 were performed at selected locations. The strains were recorded with Vishay CEA-06062UM-120 strain gauge rosettes and approximated by polynomials of fifth to seventh degree in order to compute the residual stresses.

\section{Results and discussion}

The hoop residual stresses on the outer and inner surface of a specimen welded with a preheating temperature of $\mathrm{T}_{\mathrm{p}}=150^{\circ} \mathrm{C}$ and an interpass temperature of $\mathrm{T}_{\mathrm{i}}=300^{\circ} \mathrm{C}$ are presented in Fig. 3 and 4 . As in the following figures, the stress accuracy is given for each measuring point at $\varphi=180^{\circ}$. On the outer surface, the curves on the outer surface are w-shaped along all the four lines shown in Fig. 2. The stresses in the weld seam are tensile and amount to about $150 \mathrm{MPa}$. In the base material, compressive maxima of about -100 MPa can be found, with stresses decreasing with increasing distance from the weld centerline. The tensile hoop stresses within the weld seam are due to thermal contraction, restrained by the base material as the solidifying filler metal is much warmer when the cooling process starts. For equilibrium reasons, this also causes compressive stresses in the base material. The circumferential contraction of the weld seam necessarily results in a radial contraction of the tube, which was confirmed by deformation measurements using laser triangulation. 
Near the weld toe in the HAZ, local minima with adjacent maxima in the base material occur, differing by about $100 \mathrm{MPa}$. The local maxima result from a phase transformation of austenite into bainite or martensite that occurs during cooling after welding the second pass, resulting in compressive stresses within the weld seam due to constraints impeding the volume expansion. In order to satisfy mechanical equilibrium, tensile stresses develop in the adjacent base material that remain there even after the cooling process has finished. The stress distribution due to shrinkage, as described above, is superimposed on the stresses arising from the phase transformation, resulting in the curves seen in Fig. 3.

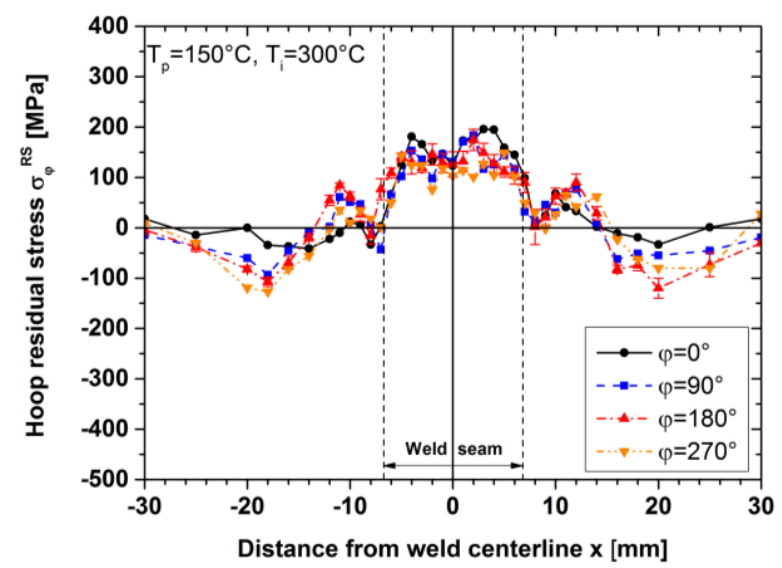

Figure 3: Hoop residual stresses on outer surface; interpass temperature $T_{i}=300^{\circ} \mathrm{C}$

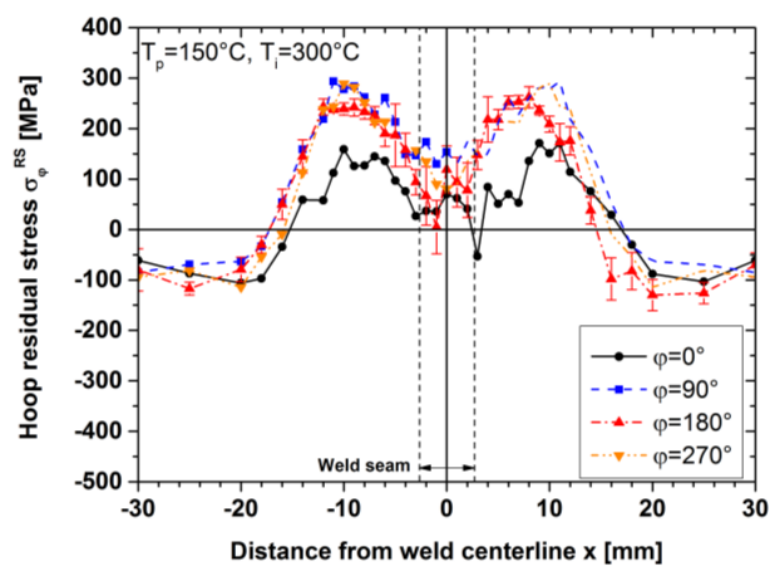

Figure 4: Hoop residual stresses on inner surface; interpass temperature $T_{i}=300^{\circ} \mathrm{C}$

Fig. 4 displays the hoop stresses on the inner surface after sectioning the tubes. Here, the curves are $\mathrm{m}$-shaped, exhibiting relatively broad areas of tensile stresses in the base material and significantly lower tensile stresses within the weld seam. Strain measurements taken at $\mathrm{x}=6 \mathrm{~mm}$ during the sectioning process revealed that the tensile stresses were even higher originally. At a distance of about $15 \mathrm{~mm}$ from the weld centerline, the hoop stresses become compressive. With the exception of the curve representing $\varphi=0^{\circ}$, which was taken at the very beginning of the first pass, the curves almost coincide. Again, the tensile stresses can be ascribed to hindered shrinkage in the vicinity of the weld seam, equilibrated by compressive stresses in more remote areas.

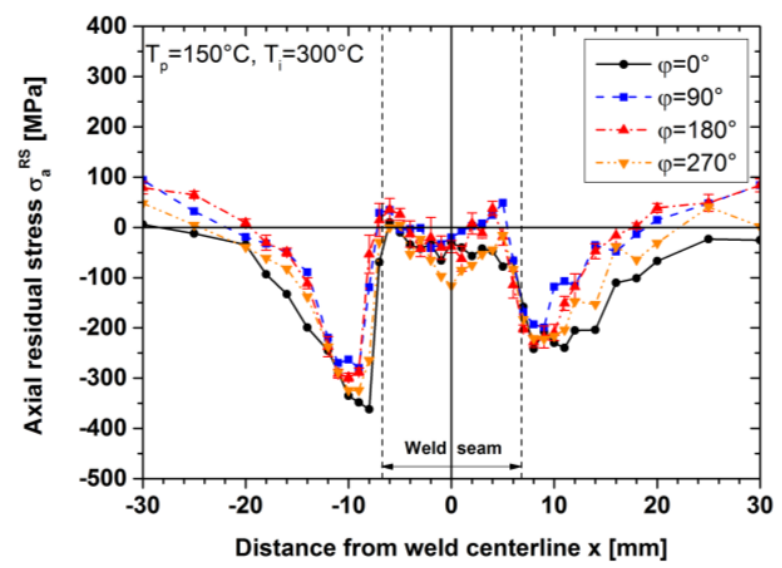

Figure 5: Axial residual stresses on outer surface; interpass temperature $T_{i}=300^{\circ} \mathrm{C}$

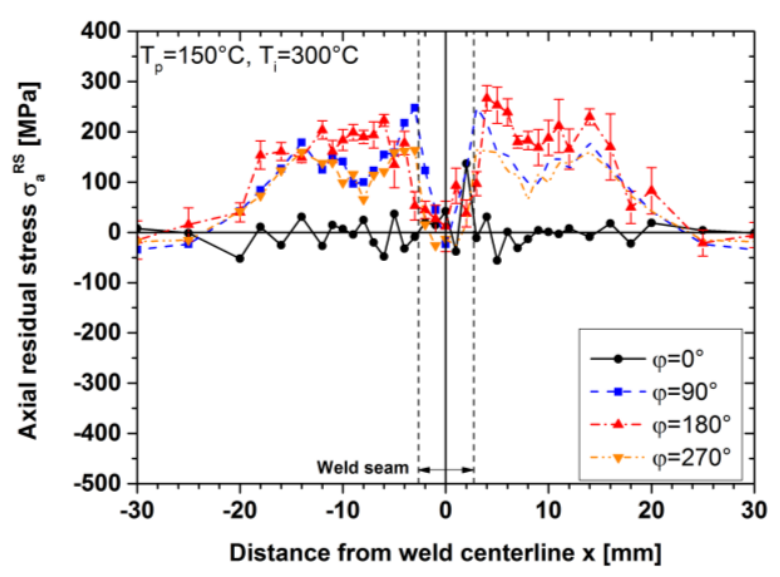

Figure 6: Axial residual stresses on inner surface; interpass temperature $T_{i}=300^{\circ} \mathrm{C}$

Fig. 5 and 6 depict the residual stresses in the axial direction on the outer and inner surface of the tubes. Again, the curves on the outer surface are w-shaped; here, they exhibit characteristic minima, i.e. compressive stresses, in the HAZ near the weld toe of up to $350 \mathrm{MPa}$. There are steep stress 
gradients between the weld toe and the weld seam, where the stresses are of low magnitude. In the base material, the compressive stresses decrease as the distance from the centerline increases and eventually reach the tensile regime with stresses of up to $100 \mathrm{MPa}$.

On the inner surface, except for the stresses at $\varphi=0^{\circ}$, the axial stress follows $m$-shaped curves, exhibiting tensile stresses between 100 and $250 \mathrm{MPa}$ in an area of up to $20 \mathrm{~mm}$ from the weld centerline, see Fig. 6 . Within the weld seam, though, the stress takes values of about $0 \mathrm{MPa}$. The strain measurements during sectioning showed that the tensile stresses in the base material were even higher in the original state of the tube.

The axial residual stresses can be explained by an interaction of several mechanisms. Firstly, the radial contraction of the tube, due to its circumferential contraction as described above, exerts a bending moment on the tube wall that, on the outer surface, generates compressive stresses in the vicinity of the weld seam and tensile stresses in greater distance to the centerline. The latter point is reflected by the tensile stresses at $|x|>20 \mathrm{~mm}$, see Fig. 5. On the inner surface, bending has a reverse effect, resulting in tensile stresses near the weld seam and compressive stresses in more remote areas. The former can be seen in Fig. 6, the latter was confirmed by single measurements at about 40 $\mathrm{mm}$ from the centerline whose results are not shown here. The mechanism described here has also been identified in austenitic steel pipes [5].

Secondly, within the weld seam and its proximity, a phase transformation of austenite into bainite or martensite occurs during cooling after welding the second pass, resulting in compressive stresses within the weld seam and its vicinity. The fact that the compressive stresses even reach the yield stress of the base material in the HAZ, which cannot be observed in welds of plane plates [3], but was also found in TIG dummy welds of steel pipes [4], can be explained by the high degree of constraint resulting from the bending stiffness of a tube which is significantly higher than the bending stiffness of a plate of the same wall thickness. Hence, bending about the weld seam caused by transverse contraction or dilatation of the weld as observed in plates is all but prevented, thus leading to higher compressive stresses. Due to equilibrium reasons, the high compressive stresses on the outer surface also lead to high tensile stresses on the inner surface.

On the outer surface, the compressive axial stresses within the weld seam resulting from phase transformations are superposed by tensile stresses caused by thermal contraction of the originally liquid filler metal. Therefore, the axial stresses found here are rather low and may be in the compressive or tensile regime. Due to axial equilibrium, the stresses on the opposite side of the tube wall have to be low as well, explaining why the axial stresses are almost negligible within the weld seam on the inner surface, see Fig. 6.

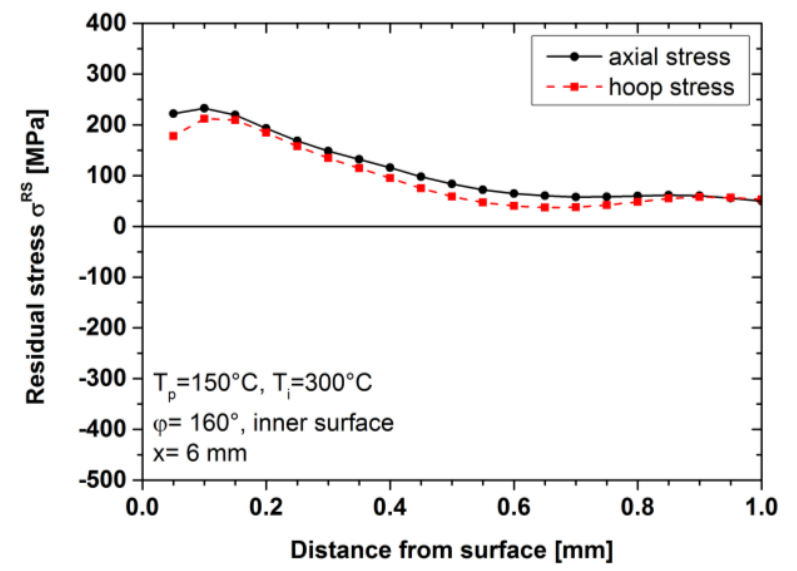

Figure 7: Residual stresses in the HAZ near the inner surface determined by the holedrilling method

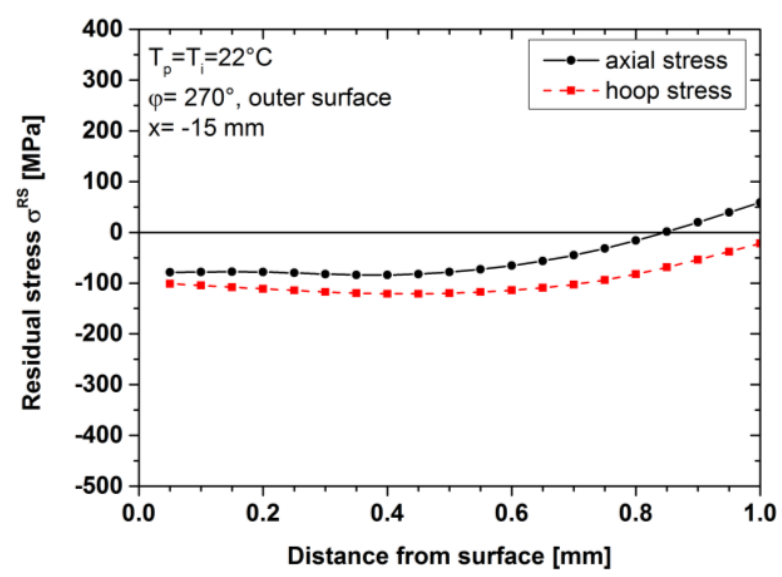

Figure 8: Residual stresses in the base material near the outer surface determined by the hole-drilling method 
With increasing distance from the inner surface in depth direction, the stresses in both hoop and axial direction decrease, as measurements using the hole-drilling method show, see Fig. 7. This confirms that bending has an influence on the axial stresses which therefore reach their maximum magnitude on the inner surface of the pipe. Additionally, the hole-drilling method was employed on the outer surface of a tube welded with $\mathrm{T}_{\mathrm{p}}=\mathrm{T}_{\mathrm{i}}=22^{\circ} \mathrm{C}$, see Fig. 8. As the hole-drilling method only provides reliable results for stresses of up to $60 \%$ of the yield strength, the measurement has not been taken near the weld toe, where very high compressive axial stresses occur, but at $\mathrm{x}=-15 \mathrm{~mm}$, where the hoop stress exhibits a minimum. While the near-surface compressive stresses seem to be underestimated, compared to the results obtained by XRD and shown in Fig. 9 and 10, it can be seen qualitatively that the stresses in both directions are nearly constant for the first $0.5 \mathrm{~mm}$. Afterwards, the compressive stresses diminish; the axial stress even enters the tensile regime, although the latter result may not be quantitatively correct. This also shows that both hoop and axial stresses vary over the wall thickness, with the highest magnitudes occurring at the surfaces.

Influence of preheating. In order to analyze the influence of using a certain preheating or interpass temperature, Fig. 9 and 10 depict the residual hoop and axial stresses, respectively, determined on the outer surface of a specimen that was welded with $T_{p}=T_{i}=22^{\circ} \mathrm{C}$. In general, it can be seen that the stress curves are similar to the ones taken from a tube that was welded with $\mathrm{T}_{\mathrm{p}}=150^{\circ} \mathrm{C}$ and $\mathrm{T}_{\mathrm{i}}=300^{\circ} \mathrm{C}$, see Fig. 3 and 5, with stress maxima and minima at the same locations. However, the absolute value of the stresses is significantly higher when no high preheating and interpass temperatures are used; the magnitudes of both tensile and compressive maxima are about $100 \mathrm{MPa}$ higher. Moreover, the local hoop stress maxima in the HAZ are less distinct and less wide, as seen in Fig. 9. It also becomes evident that the differences between varying circumferential angles are more pronounced. Within the weld seam, the curves of both the hoop and the axial stresses are shifted downwards as the circumferential angle, i.e. the time since the welding start, increases.

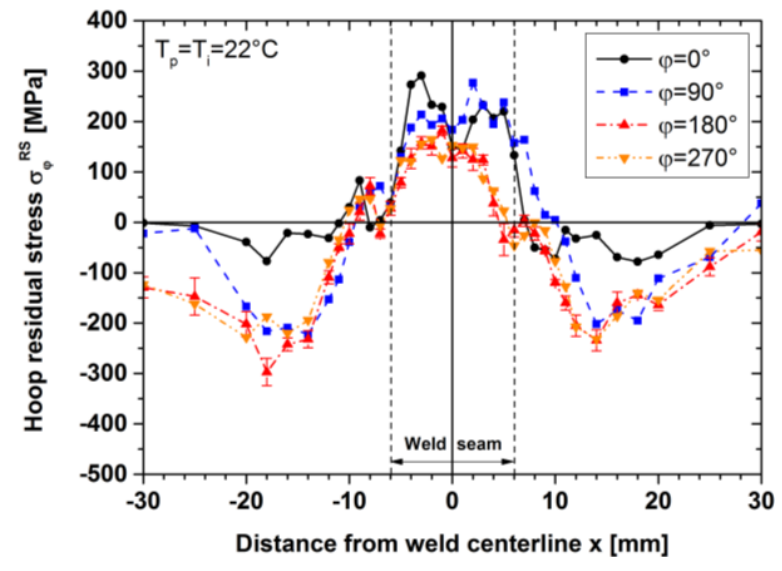

Figure 9: Hoop residual stresses on outer surface; interpass temperature $T_{i}=22^{\circ} \mathrm{C}$

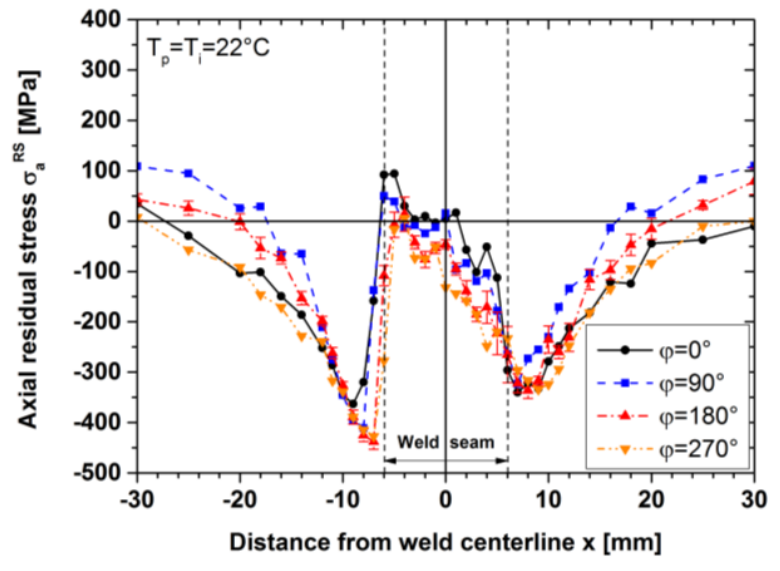

Figure 10: Axial residual stresses on outer surface; interpass temperature $T_{i}=22^{\circ} \mathrm{C}$

A well-known model [3] qualitatively explains the development of residual stresses as an interaction between thermal shrinkage and volume expansion due to phase transformation. It is stated that the cooling rate, i.e. eventually the temperature where the transformation from austenite to ferrite, bainite or martensite occurs, controls the influence that the phase transformation exerts on the eventual residual stress state. The lower the cooling rate, i.e. the higher the transformation temperature, the more are the compressive stresses limited by the relatively low yield stress at high temperatures and the higher are the tensile stresses due to subsequent thermal shrinkage.

In the current study, it was found through temperature measurements at the weld toe that high preheating and interpass temperatures significantly influence the cooling rate. After welding the second pass with an interpass temperature of $\mathrm{T}_{\mathrm{i}}=22^{\circ} \mathrm{C}$, the time needed for cooling down from $800^{\circ} \mathrm{C}$ to $500^{\circ} \mathrm{C}$, amounted to 14 seconds, compared to 28 seconds after welding with $\mathrm{T}_{\mathrm{i}}=135^{\circ} \mathrm{C}$. It is inferred that the cooling time is even longer for higher temperatures, e.g. $\mathrm{T}_{\mathrm{i}}=300^{\circ} \mathrm{C}$. Despite the 
large difference in cooling rates, it was not observed that higher tensile stresses occur; on the contrary, the tensile hoop stresses in the weld seam are lower for $\mathrm{T}_{\mathrm{i}}=300^{\circ} \mathrm{C}$ than for $\mathrm{T}_{\mathrm{i}}=22^{\circ} \mathrm{C}$. However, the fact that the characteristic compressive axial stresses in the HAZ are significantly lower for $\mathrm{T}_{\mathrm{i}}=300^{\circ} \mathrm{C}$ could be explained according to the model mentioned above [3].

The preheating or interpass temperature mainly has an influence on the residual stresses due to thermal shrinkage. As the temperature difference between the weld metal and the base material is reduced, so is the degree of constraint, leading to lower tensile stresses. This is reflected by lower hoop stresses within the weld seam on the outer surface and therefore lower equilibrating compressive stresses in the base material. It also explains why, despite the lower compressive stresses in the HAZ, the axial stresses do not take significant tensile values in the weld seam for $\mathrm{T}_{\mathrm{i}}=$ $300^{\circ} \mathrm{C}$, see Fig. 5. The downshift of the stress curves in the weld seam with increasing welding time, as seen in Fig. 9 and 10, can be interpreted as an effect of the gradual warming of the tube. The longer the welding process takes, the more does the tube heat up, leading to the same effects as described for a high preheating or interpass temperature and thus to lower tensile stresses.

\section{Summary and conclusions}

The residual stresses on the outer and inner surface of multi-pass butt-welded tubular joints of the ferritic-pearlitic steel $\mathrm{S} 355 \mathrm{~J} 2 \mathrm{H}+\mathrm{N}$ have been determined by X-ray diffraction and the hole-drilling method. It was shown that the residual stress profiles can be explained by the mechanisms of hindered thermal shrinkage and hindered volume expansion due to phase transformation. Analysis of the hoop stresses demonstrated that thermal shrinkage of the weld seam is the governing mechanism in the development of residual stresses in the tubular joints studied here. Through circumferential and thus radial contraction of the weld the axial stress distribution is influenced significantly, hence showing a distinctly different behavior than in welded plates. It could be seen that using a high preheating or interpass temperature, though decreasing the cooling rate, did not essentially affect the residual stress distributions by altering their development mechanisms. It did, however, reduce the constraint of thermal shrinkage and therefore tensile residual stresses.

\section{Acknowledgement}

We would like to thank the German Federation of Industrial Research Associations (AiF) for its financial support of the research project IGF No. 17.619N. This project was carried out under the auspices of AiF and financed within the budget of the Federal Ministry for Economic Affairs and Energy through the program to promote joint industrial research and development (IGF).

\section{References}

[1] A. Hobbacher, Recommendations for Fatigue Design of Welded Joints and Components, IIWDocument, XIII-2151-07 / XV-1254-07, 2007.

[2] EN 1993-1-9 (Eurocode 3): Design of Steel Structures, Part 1.9: Fatigue, CEN, Brussels, Belgium, 2005.

[3] T. Nitschke-Pagel, H. Wohlfahrt, Residual Stress Distributions after Welding as a Consequence of the Combined Effect of Physical, Metallurgical and Mechanical Sources, in: L. Karlsson, L.E. Lindgren, M. Jonsson (Eds.), Mechanical Effects of Welding, IUTAM Symposium Lulea/Sweden 1991, Springer Verlag, Berlin, 1992, pp. 123-134.

[4] M. Farajian, T. Nitschke-Pagel, K. Dilger, Welding Residual Stresses in Tubular Joints, Materials Science Forum 768-769 (2013) 605-612.

[5] D. Deng, H. Murakawa, W. Liang, Numerical and experimental investigations on welding residual stress in multi-pass butt-welded austenitic stainless steel pipe, Computational Materials Science 42 (2008) 234-244. 